elderly population fell. As I reported in $1972,{ }^{3}$ the geriatric turnover rate in the city had plunged to a low level. Counteracting this trend to some extent, the discharge rate of persons aged 65 and over from medical departments rose dramatically at a rate of $6.9 \%$ per annum from 1966 to 1971 compared with only $2.8 \%$ per annum for patients under the age of 65 . In spite of this rise, the rate will have to accelerate to match the increasing demand for emergency admissions. The trend must eventually be selflimiting because older patients stay longer in hospital and their increasing numbers will lower the rate of turnover in medical departments. We are approaching, and have already in some districts of Birmingham reached, the critical mark where, as Dr. Boyd points out, low-turnover/long-waiting-list geriatric services become the rule and public need can no longer be met either in full or even up to present standards. In short, the hospital service in these areas is failing the old progressively. Dr. Boyd records passing the critical point at Greenwich when his bed ratio fell below 11.1 beds per 1,000 population aged 65 and over. One must accept that local variations in the critical level are bound to occur, but it is important to remember that even where the number of ger:a ric beds remains unaltered the increased numbers of elderly are steadily reducing the number of beds per head of the population -that is, bed coverage for the elderly is falling.

To reverse the present trend in which medical emergencies, especially in the elderly, overflow into and flood other hospital departments it is necessary to increase the geriatric side and restore the balance to a position nearer the national "norm." The price of failure to do this will be breakdown of hospital emergency services in those areas which neglect the old. It is to be expected that physicians working under great pressure should demand more beds and staff and use their built-in majority in a Cogwheel administration to press their claims. Bur if we compare the saving to the hospital service of a physician doubling his turnover with the effect of a geriatrician achieving the same thing, we find that a physician would save less than 10,000 bed days each year, whereas a geriatrician would save more than 100,000 bed days annually. Inpatient care is the most expensive resource dispensed by the hospital service and it is evident that greater potential saving lies in more concentrated effort to reduce the hospital stay of geriatric patients. The scale of provision required is known from census figures for years to come-most of us alive today are in the queue for geriatric care.-I am, etc.,

R. W. PARNELI Highcroft Hospital,

Birmingham

1 National Health Service Hospital Advisory Service, Annual Report for 1972. London, H.M.S.O. 1973.

2 Department of Health and Social Security, Report on Hospital In-Datient Enquiry for the Year Parnell, 760.

\section{Experiments on Children}

SIR,-A view accepting as ethical the use of children in experiments not directly bene- ficial to them, provided that these investigations are of negligible risk and potential medical value and that informed parental consent is obtained, has been put forwand in two recent publications. ${ }^{2}$

The editorial in the October edition of Archives of Disease in Childhood ${ }^{1}$ is of particular interest because it is immediately followed by a paper ${ }^{3}$ describing an investigation on children with measles in Nigeria in which non-therapeutic procedures were carried out both on diseased children and on their unaffected sibs. Each patient appears to have undergone two blood test and two sets of three intradermal skin tests, and also the application of sensitization and challenge doses of dinitrochlorobenzene, in addition to a normal treatment regimen Their sibs underwent a similar series of tests.

The editorial referred to above suggests as a reductio ad absundum the slight risk and comparative benefit of extra weighing of children as a mode of investigating different feeding methods. It is possible to question whether this situation is quite as absurd as it seems, though one would no go so far as to condemn it as unethical. Here is a case of an individual being subjected without his or her knowledge or consent to an investigation which, like venepuncture, undoubtedly causes discomfort This is not a question of "risk of harm"harm of an uncertain degree is caused by the act of venepuncture or by the act of weighing, since many young children and babies are manifestly upset while these tests are performed.

Is it the function of the doctor to cause suffering to an individual patient, considering the patient in an epidemiological context rather than in an interpersonal relationship? Should a child lose his right as an individual simply because he is immature and because his suffering cannot be measured; and should he become susceptible to the doubtful judgement of others as to what constitutes potential medical progress in world where so much progress is illusory?

Though, as Curran and Beecher ${ }^{2}$ have pointed out, it is possible to ridicule a "strict" ethical approach by invoking othe aspects of normal life in childhood, I think that there may be a case for saying that neither a doctor nor an ethical committee should be in a position to participate in an assault on a child. Perhaps the function of the doctor should remain to act only in the direct interest of his patient, so that the individual doctor-patient relationship remains sacrosanct until the child is of an age to make up its own mind.

I very much doubt whether the lack of medical knowledge and increase in suffering resulting from this attitude could no be made good by a more positive approach to that relatively neglected realm of the doctor's job, the art of reconciling the patient to those factors in his life, whether or not involving a recognized illness, which make him suffer-the more overtly "physicianlv" aspects of medical care. Looking at medical research in a historical context, it should take its place as a luxury, albeit a very important and stimulating one, beside the direct relief of suffering; it should be expendable when necessary.-I am, etc.,

\section{A. E. Tulloch}

St. Thomas's Hospital London S.E.
1 Archives of Disease in Childhood, 1973, 48, 751. Curran, W. J., and Beecher, H. K., Fournal of the American Medical Association, 1969, 210, 77. Whittle, H. C., Bradley-Moore, A., Fleming, A., Childhood, 1973, 48, 753.

\section{Norwegian Scabies during \\ Immunosuppressive Therapy}

SIR,-Dr. W. D. Paterson and his colleagues (27 October, p. 211) have added therapy with immunosuppressive drugs to other known predisposing factors in Norwegian scabies, and this is not surprising. Dostrovsky et al.,1 cited by these authors, as well as Tanaka and Usuba ${ }^{2}$ and Logan et al. $^{3}$ have reported this infestation in connexion with the leukaemias, and these are diseases of suppressed immunity.

What I found unusual in their case report was the prompt and complete response to $1 \%$ gamma-benzene hexachloride, for I have found that repeated applications of benzyl benzoate are inadequate, these cases responding only to a prolonged course of continuous inunction with $10 \%$ sulphur ointment. Reversion to this discarded form of therapy has also been found necessary in dealing with epidemics of ondinary scabies affecting geriatric or mentally subnormal patients in institutions, whether or not arising from the orusted form of the disease. This would suggest either resistance developing on the part of the acarus to medicaments in current use or difficulty in applying these remedies in this type of patient. -I am, etc.,

Department of Dermatology,

Glasgow

JAMES C. P. LOgaN

1 Dostrovsky, A., Raubitschek, F., and Sagher, F. Dermatologica. 1956, 113. 26.
Tanaka, T. and Usuba, M., Tohoku fournal of Experimental Medicine, 1960. 72, 35

3 Logan, J. C. P., Grant, P. W., and Keczkes, K.,

SIR,-I was interested to read the article by Dr. W. D. Paterson and others (27 October, p. 211).

In $1970 \mathrm{I}$ was supervising the terminal illness of a woman suffering from carcinomatosis who had received radiotherapv and who was on continual steroid therapy (dexamethasone $2 \mathrm{mg}$ thrice dailv), when the skin of her body-save for that of her scalp, face, and neck-became covered remorselesslv bv a series of crusts and scales, with hvperkeratosis especially evident around the nailfolds. A striking feature was the absence of itching.

Such was the degree of desquamation that her bed linen and the immediate surroundings of her bed were covered with scales, manv of which came into contact with her husband, daughter, nurse, and mvself. Further contaot with the rash was inevitable in the course of nursing care and examination. About 3-4 weeks later all of us develooed scabies. Onlv the expertise of a consultant dermatologist unrave'led the mystery. Having seen the patient and heard the complaint of her attendants he unhesitatingly diagnosed Norwegian scabies, which was confirmed by microscopical evidense of abundant acari and eggs in a skin biopsy.

There seems no doubt that steroids can alter the reaction of the skin to parasitic invasion, and at a time when scabies is on the increase the possibility of Norwegian 